\title{
Setting Sail Into a New Decade
}

\author{
Athena Trakadas ${ }^{1} \cdot$ Annalies Corbin ${ }^{2}$
}

Published online: 21 February 2020

(c) Springer Science+Business Media, LLC, part of Springer Nature 2020

As we now enter the second decade of the twenty-first century, there are several milestones to note with the Journal of Maritime Archaeology (JMAR). In 2010, Annalies Corbin and Athena Trakadas joined the journal's founding editor, Jonathan Adams, and in 2015 became Co-Editors-in-Chief when he stepped down. We endeavour to carry on JMAR's mission and vision established by Jon in 2006, while simultaneously expanding both the reach and content of the journal now under our stewardship. In 2020, JMAR sets sail to publish four issues per year.

The new decade also provides the opportunity for us to look back upon the changes and growth of the journal since our last editorial, five years ago. In 2015, JMAR increased publication from two to three issues a year. During this five-year period, five volumes of 15 issues-223 original articles in total-were published, well over double of what the journal published in the first ten years of its existence. These articles have been accompanied by editorials, commentaries and an increasing number of book, conference and exhibit reviews. In the last year alone, over 33,000 JMAR articles were downloaded, with some individual articles downloaded over 6000 times. This progress is consistently being noted though increasing impact factors with CiteScore and SCImago Journal Rank (SJR) (currently 75 out of 259 in Archaeology/Arts and Humanities). The journal is also rated ' $A$ ' in both the European Reference Index for the Humanities and the Australian Research Council Humanities and Creative Arts Journal List.

In our last editorial (Trakadas and Corbin 2015: 10), we expressed our hopes for expanding the geographical representation of authors and subject matter for the journal's content, particularly from the Central and South America and the Asia/Pacific regions. Being mindful of the nascent development of the practice of maritime archaeology and Underwater Cultural Heritage (UCH) management in parts of these regions, we have achieved some success: articles addressing projects, issues and debates from here have been published and have also been the subjects of special thematic issues (discussed below). While we actively promote submissions globally, however, we are aware that this goal has not yet been fully met. We especially would like to publish more articles deriving from Africa, the broader Indian Ocean region and South-east and Central Asia.

Athena Trakadas

Athena.Lynn.Trakadas@natmus.dk

Annalies Corbin

annalies@pastfoundation.org

1 National Museum of Denmark, Copenhagen, Denmark

2 The PAST Foundation, Columbus, OH, USA 
The aims of the journal were slightly adjusted in 2015, and these remain the same in 2020: “...to address all aspects of maritime archaeology, both terrestrial and under water. [The Journal] encompasses theory, practice and analysis relating to sites, technology, landscape, structure and issues of heritage management. The Journal provides a conduit for maritime approaches reaching across archaeology and related disciplines such as cultural geography, history, ethnography, oceanography and anthropology. In so doing the journal addresses all aspects of the human past relating to maritime environments." (JMAR, n.d.)

We continue to advocate for more papers addressing methodology, ethics, dissemination strategies, the management of $\mathrm{UCH}$ and Maritime Cultural Heritage $(\mathrm{MCH})$ and the conservation of sites. Reviews and commentary of specific arguments for and against the ratification of the UNESCO 2001 Convention on the Protection of the Underwater Cultural Heritage are also sought, now that the tenth anniversary of the Convention's going into effect has just been reached.

The journal has successfully chronicled maritime research from the Mesolithic to WW II. Thematically, JMAR has also published articles examining material culture particularly relating to shipboard life, fishing practices and the extraction and production of natural marine resource (salt, oils, bitumen), and ethnographic studies of fishing, boatbuilding and maritime cultural landscapes. Such range can hopefully be seen in the articles published in this present volume. We would like to see more articles presenting harbours/coastal sites (particularly in the light of rising sea levels and the effects of climate change) and management issues related to these, marine spatial planning and heritage management (especially related to the impending implementation of the UN Decade of Ocean Science for Sustainable Development 2021-30), the archaeology of inland waters and gender studies.

The last five years have also included five Special Issues: Issue 11.1 (2016): Maritime Archaeology of the Cold War: EX-USS Independence (as a Case Study), Robert S. Neyland, guest editor; Issue 12.3 (2017): Recent Ideas and Actors in Latin American Maritime Archaeology (Ideas y Actores Recientes en la Arqueología Marítima Latinoamericana), Arturo Rey Da Silva and Jorge Manuel Herrera Tovar, guest editors; Issue 13.2 (2018): Maritime Archaeology on the Final Frontier: Telepresence-enabled Robotic Missions into the Deep, Michael L. Brennan and James P. Delgado, guest editors; Issue 13.3 (2018): The Bountiful Sea: Fish Processing and Consumption in Mediterranean Antiquity. Proceedings of the International Conference Held at Oxford, 6-8 September 2017, Dimitra Mylona and Rebecca Nicholson, guest editors (our largest issue yet, with 16 articles); Issue 14.3 (2019): Maritime Cultural Heritage and the Challenges of Capacity Development, Lucy Blue and Colin Breen, guest editors. The diverse titles of the Special Issues are themselves reflective of the journal's aims.

Over the last five years, we have also actively grown the number of book reviews in the journal. We said farewell to reviews editor Helen Farr (University of Southampton), who moved on to focus on her own research and growing family. We will be forever indebted to Helen for her time, attention and dedication to ensuring that JMAR was well-positioned to continue to expand the book review offerings in the coming years. In mid-2018, we welcomed Madeline Fowler (University of Southampton) as JMAR's new book reviews editor and looked forward to expanding the wide range of reviewed volumes for our readers during her tenure.

As with the journal's development of its reach and scope, and to keep up with the advances in the field of maritime archaeology, its Editorial Board has reflected these movements: the board has included and continues to include representatives that broadly reflect the description and aims of the journal, thematically and methodologically. We also strive to allow for a wider geographical reach of scholars, reflecting, we hope, the practice around 
the globe. With this issue, we welcome Andrew Viduka and Himanshu Prabha Ray to the board, and in 2019, we welcomed Chris Underwood. They join a supportive and active board whose members include Dionisius Agius, Lucy Blue, Giulia Boetto, Richard Bradley, Justin Dix, Jerzy Gawronski, Matthew H. Johnson, Emad Khalil, Margaret E. LeshikarDenton, Seán McGrail, David Mindell, Arturo Rey da Silva, Nathan Richards, Matthew A. Russell, Fraser Sturt and Jonathan Sharfman. We are grateful to their assistance in promotion of JMAR and commitment to helping it develop and fulfil its aims.

With the new decade, we continue our aim to hold aloft one of JMAR's original purposes: to publish high-quality and diverse maritime archaeological and related research that has not yet found a home port. As we continue to widen the breadth and depth of the contributions coming to the journal, we invite you to be part of our voyage.

\section{References}

JMAR (n.d.) J Marit Archaeol Aims Scope. https://www.springer.com/journal/11457/aims-and-scope. Accessed 22020

Trakadas A, Corbin A (2015) Looking towards the horizon: a decade on.... J Marit Archaeol 10(1):7-10

Publisher's Note Springer Nature remains neutral with regard to jurisdictional claims in published maps and institutional affiliations. 